\title{
$5-15-2011$
}

\section{MMP-13 Selective Alpha-sulfone Hydroxamates: Identification of Selective P1' Amides}

\author{
Yvette M. Fobian \\ Pfizer Research \& Development \\ John N. Freskos \\ Pfizer Research \& Development \\ Thomas E. Barta \\ Pfizer Research \& Development \\ Louis J. Bedell \\ Pfizer Research \& Development \\ Daniel Becker \\ Loyola University Chicago, dbecke3@luc.edu \\ Follow this and additional'works at: https://ecommons.luc.edu/chemistry_facpubs \\ Part of the Chemistry Commons \\ Author Manuscript \\ This is a pre-publication author manuscript of the final, published article.
}

\section{Recommended Citation}

Fobian, Yvette M.; Freskos, John N.; Barta, Thomas E.; Bedell, Louis J.; and Becker, Daniel. MMP-13 Selective Alpha-sulfone Hydroxamates: Identification of Selective P1' Amides. Bioorganic \& Medicinal Chemistry Letters, 21, 10: , 2011. Retrieved from Loyola eCommons, Chemistry: Faculty Publications and Other Works, http://dx.doi.org/10.1016/j.bmcl.2011.03.095

This Article is brought to you for free and open access by the Faculty Publications and Other Works by Department at Loyola eCommons. It has been accepted for inclusion in Chemistry: Faculty Publications and Other Works by an authorized administrator of Loyola eCommons. For more information, please contact ecommons@luc.edu. c) () $\odot$

This work is licensed under a Creative Commons Attribution-Noncommercial-No Derivative Works 3.0 License. (c) 2011 Elsevier 
MMP-13 Selective $\alpha$-Sulfone Hydroxamate Flexible Chain P1' Amides

John N. Freskos, Yvette Fobian, Thomas E. Barta, Heintz, James R. Kiefer, Brent V. Mischke, Patrick Mullins, Grace E. Munie, Daniel P. Becker

Abstract: Continuing our interest in designing compounds preferentially potent and selective for MMP-13, we report on a series of hydroxamic acids with a flexible amide P1' substituents. We identify an amide which spares both MMP-1 and -14 , and shows $>500$ fold selectivity for mmp-13 vs. MMP-2 and -8 .

Matrix Metalloproteinases (MMPs) are a family of about 27 zinc-dependent enzymes responsible for the turnover of collagen in connective tissue. There are a variety of disease states where degradation of collagen contributes to the pathology, specifically, in osteo- and rheumatoid arthritis; in tumor angiogenesis and metastasis; and in post-MI cardiovascular remodeling. ${ }^{1}$ In spite of the promise that modulation of MMP activity offers, the road from proof of concept to pharmacy shelves has been a long one. Clinical compounds often induce a dose-limiting jointstiffening often referred to as musculoskeletal syndrome (MSS).

It has been hypothesized that inhibition by drug candidates of MMP-1, a constitutive enzyme involved in the turnover of type II collagen, contributes to MSS. ${ }^{2 a}$ Sparing MMP-1 may not be sufficient. In our earlier research we saw that dosing with the MMP-1 sparing hydroxamate 1 (SC-276, Figure 1) eventually led to joint stiffening. ${ }^{2 b}$ MT1-MMP (MMP-14) may also play a role in MSS, since it has been observed that MMP-14 knockout mice suffer from joint lesions reminiscent of the changes in MSS. ${ }^{3}$ The actual situation may be even more complex; MMP inhibitors that spare both MMP-1 and -14 may bind to members of the structurally-related ADAMs family (A Disintegrin And Metalloprotease), ${ }^{4}$ leading to undesired joint effects.

An alternative approach toward realizing efficacious MMP inhibitors with reduced side effects is to focus on optimizing the inhibition of the single MMP isoform that should confer the most therapeutic benefit, reducing the probability of off-target protease inhibition. MMP-13 is an attractive isoform to pursue; MMP-13 rapidly degrades type II collagen and is associated with pathology. The isoform is upregulated in osteoarthritic joints and in cancer. ${ }^{5}$ Structural studies show that MMP-13 differs from other MMP's in the depth of its S1' pocket, suggesting that lengthier inhibitors may confer selectivity.

With this in mind, we previously reported a series of rigid piperidino- ketones (compound $\mathbf{2}$, Figure 1) with lengthier P1' subunits and, with optimization, we achieved significant selectivity for MMP-13 vs. other MMP isoforms. ${ }^{6,7}$ Although potent and selective, ketones like 2 exhibited poor PK, so we endeavored to improve their ADME properties, in part, though reduction of 
molecular weight. Conceptually dissecting the piperidine ring in compound 2 led to acyclicchain analogs such as ketone 3a (Figure 1).

The synthesis of ketone 3a and related ketones (e.g. 3b, Scheme 1) proceeded from aryl fluoride $4,{ }^{8}$ which was reacted with an omega benzyloxy 1 -alkanol. The benzyl alcohol could be cleaved by hydrogenation and the resulting alcohol oxidized to a carboxylic acid. This acid, $\mathbf{6}$, was converted using EDC coupling to a Weinreb amide ${ }^{9}$ and the t-butyl ester was treated with TFA to liberate the acid on the left hand side of the molecule, and this acid was coupled with $\mathrm{THPONH}_{2}$. Excess aryl Grignard and subsequent treatment with $\mathrm{HCl}$ led to the final product, $\mathbf{3 b}$. Similar straightforward chemistry could be used to arrive at amides like $\mathbf{1 6 a}$.

Isomeric amides (Scheme 2) could be obtained using, for example, tert-butyl N-(3hydroxypropyl)carbamate, which could be carried on to amine $\mathbf{9}$. Amine 9 was converted to amide analogs 10, and on to final hydroxamic acids 12a.

We synthesized over 500 extended chain amides and ketones in our MMP-13 program and the findings foe selected analogs are summarized in Table 1. Isonipecotate $\mathbf{2}$ demonstrates excellent selectivity for MMP-13 vs. the other MMP isoforms tested. The direct open-chain analogs of $\mathbf{2}$, ketones 13, 14, and 3a, which differ in connecting chain length, are each are more potent toward MMP-13 than isonipecotate 2. Compounds $\mathbf{1 4}$ and $\mathbf{3 a}$ achieve encouraging selectivity ratios for MMP-13 vs. MMP-8, -9, -1, and -14, but exhibit poor selectivity with respect to MMP-2.

We looked at different linkers. Ether-linked compounds, like 17, lacked MMP-13/-2 selectivity. Amide analogs 15a and $\mathbf{1 6}$ show a significant dimunition of selectivity, with $\mathbf{1 6}$ being essentially equipotent for -8 and -13 . N-Methylation, to alter the steric environment, did not improve the ratios, as can be seen from $\mathbf{1 5 c}$ and $\mathbf{1 5 d}$.

The benzamides of Scheme 2 looked significantly more attractive; compound $\mathbf{1 2 b}$, for example, is potent for MMP-13, but unlike some of our earlier compounds spares MMP-2. Compounds 12a and 12c also had desirable profiles. Conjugation of the amide $\pi$ system into the aryl ring may diminish the conformational mobility of these amides $v s$. the amides of Scheme 1 (e.g. 12c vs 15a) and this might account for the improved selectivity of the latter series. In general, the electronics of ring substitution did not have a pronounced effect on potency/selectivity, but more hindered analogs, such as 12d, saw a drop off in activity. We also looked at "non-aryl" amides, including $\mathbf{1 2 e}$ and $\mathbf{1 2 f}$, and the compounds tested showed reduced potency and/or selectivity.

Benzamides like 12a and 12c became the focus of further study, and, while we achieved meaningful levels of MMP-13 selectivity, we did not find amides that had both high potency and acceptable PK properties. Compound 12a had a half-life in rats of $0.58 \mathrm{~h}$ (BA 1.5\%), presumably due to in vivo amide hydrolysis, and that was typical of the series. To address this issue, non- 
hydrolyzable bioisosteric replacements for the amide linkage were sought, as reported in the following Letter.

\section{References and Notes}

1. Inhibition of Matrix Metalloproteinases: Therapeutic Applications; Greenwald, R.A.; Zucker, S.; and Golub, L.M. eds. New York: New York Academy of Sciences, 1999.

2. a) Becker, D.P.; Villamil, C.I.; Barta, T.E.; Bedell, L.J.; Boehm, T.L.; Decrescenzo, G.A.; Freskos, J.N.; Getman, D.P.; Hockerman, S.L.; Heintz, R.; Howard, S.C.; Li, M.H.; McDonald, J.J.; Carron, C.P.; Funckes-Shippy, C.L.; Mehta, P.P.; Munie, G.E.; Swearingen, C.A. J. Med. Chem. 2005, 48, 6713-30. b) Becker, D. P.; Barta, T. E. Bedell, L. J.; Boehm, T. L. Bond, B. R.; Carroll, J.; Carron, C. P.; DeCrescenzo, G. A.; Easton, A. M.; Freskos, J. N.; Funckes-Shippy, C. L.; Heron, M.; Hockerman, S. L.; Howard, S. C.; Kiefer, J. R.; Li, M. H.; Mathis, K. J.; McDonald, J. J.; Mehta, P. P.; Munie, G. E.; Sunyer, T.; Swearingen, C. A.; Villamil, C. I.; Welsch, D.; Williams, J. M.; Yu, Y.; Yao, J. J. Med Chem. in press.

3. (a) Holmbeck, K.; Bianco, P.; Caterina, J.; Yamada, S.; Kromer, M.; Kuznetsov, S. A.; Mankani, M.; Robey, P. G.; Poole, A. R.; Pidoux, I.; Ward, J. M.; Birkedal-Hansen, H. Cell 1999, 99, 81-92. (b) Zhou, Z.; Apte, S. S.; Soininen, R.; Cao, R.; Baaklini, G. Y.; Rauser, R. W.; Wang, J.; Cao, Y.; Tryggvason, K. Proc. Natl. Acad. Sci. U.S.A. 2000, 97, 4052-4057.

4. Wasserman, Z.R. Chemistry and Biology 2005, 12, 143-4.

5. (a) Johnson, A.R.; Pavlovsky, A.G.; Ortwine, D.F.; Prior, F.; Man, C.F.; Bornemeier, D.A.; Banotai, C.A.; Mueller, W.T.; McConnell, P.; Yan, C.; Baragi, V.; Lesch, C.; Roark, W.H.; Wilson, M.; Datta, K.; Guzman, R.; Han, H.K.; Dyer, R.D. J. Biol Chem. 2007, 282, 27781-91. (b) Engel C.K.; Pirard B.; Schimanski S.; Kirsch R.; Habermann J.; Klingler O.; Schlotte V.; Weithmann K.U.; Wendt K.U. Chem. Biol. 2005, 12, 143-4.

6. Kolodziej, S. A.; Hockerman, S. L.; DeCrescenzo, G. A.; McDonald, J. J.; Mischke, D. A.; Munie, G. E.; Fletcher, T. R.; Stehle, N.; Swearingen, C.; Becker, D. P. Bioorg. and Med. Chem. Lett. 2010, 20, 3561. See also: Kolodziej, S. A.; Hockerman, S. L.; Boehm, T. L.; DeCrescenzo, G. A.; McDonald, J. J.; Mischke, D. A.; Munie, G. E.; Fletcher, T. R.; Stehle, N.; Swearingen, C.; Becker, D. P. Bioorg. and Med. Chem. Lett. 2010, 20, 3557.

7. For other groups interested in MMP-13 selective inhibitors: (a) Wu, J.; Rush III, T.S.; Hotchandani, R.; Du, X.; Geck, M.; Collins, E.; Xu, Z.B.; Skotnicki, J.; Levin, J.I.; Lovering, F.E. Bioorg. Med. Chem. Lett. 2005, 15, 4105-4109 (b) Nuti, E.; Casalini, F.; Avramova, S.I.; Santamaria, S.; Cercignani, G.; Marinelli, L.; La Pietra, V.; Novellino, E.; Orlandini, E.; 
Nencetti, S.; Tuccinardi, T.; Martinelli, A.; Lim, N.; Visse, R.; Nagase, H.; Rossello, A. Journal of Medicinal Chemistry 2009, 52, 4757-4773.

8. Freskos, J.N.; Fobian, Y.M.; Barta; T.E.; Becker, D.P.; Bedell, L.J.; Boehm, T.L.; Carroll, J.N.; DeCrescenzo, G.A.; Hockerman, S.L.; Kassab; D.J.; Kolodziej, S.A.; McDonald, J.J.; Mischke, D.A.; Norton, Monica B.; Rico, J.G.; Talley; J.J.; Villamil, C.I.; Wang, Lijuan J. U.S. Patent 6,890,928, 2005; Chem. Abstr. 1999, 131, 44740.

9. Nahm, S.; Weinreb, S. M. Tetrahedron Lett. 1981, 22, 3815-3818.

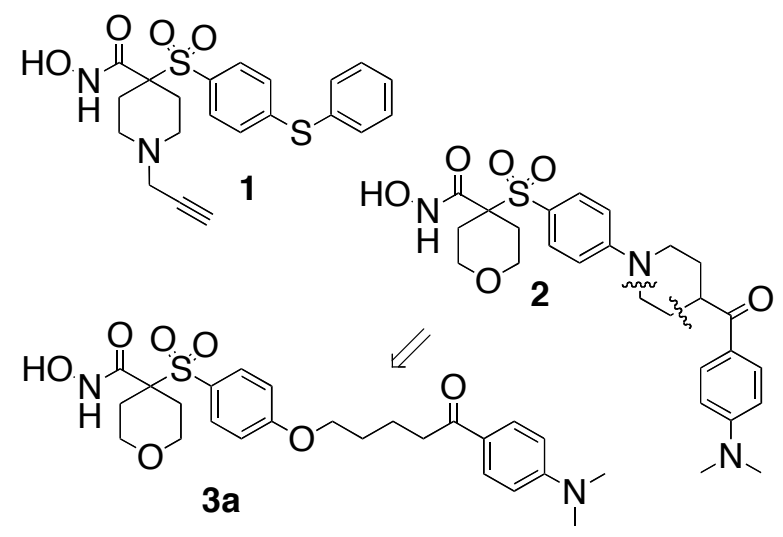

Figure 1. MMP inhibitors. Compound 1 spares MMP-1; Compounds 2 and 3 are MMP-13 selective. 
<smiles>CC(C)(C)OC(=O)C1(S(=O)(=O)c2ccc(F)cc2)CCOCC1</smiles>

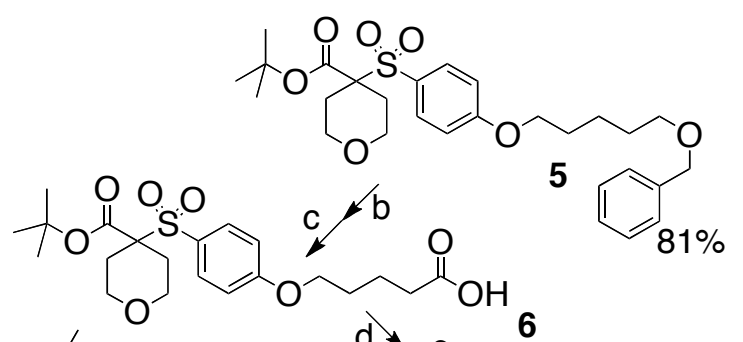

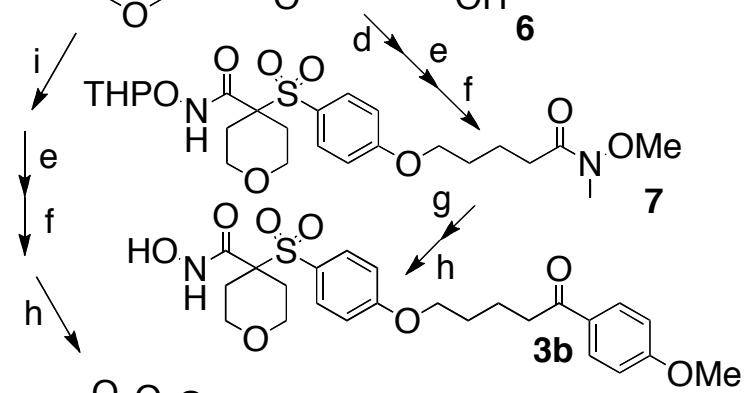<smiles>COc1ccc(NC(=O)CCCCOc2ccc(S(=O)(=O)C3(C(=O)NO)CCOCC3)cc2)cc1</smiles>

Scheme 1. Reagents and Conditions: (a) X (1.05 eq), $\mathrm{NaH} 1.2$ (eq), $0^{\circ} \mathrm{C}$-r.t., 4 h. (b) $5 \% \mathrm{Pd} / \mathrm{C}$ (wet), $80 \mathrm{psi}, \mathrm{THF}, 1.5 \mathrm{~h}$ quant. (c) $2.5 \% \mathrm{RuCl} 3, \mathrm{NalO} 4$ (3 eq), $\mathrm{CCl} 4$, water, quant (d) triethylamine (6.0 eq), Nhydroxybenzotriazole (1.5 eq), $\mathrm{HN}(\mathrm{Me}) \mathrm{OMe}(3.0$ eq), EDC (1.4), DMF, $16 \mathrm{~h} \mathrm{(e)} \mathrm{trifluoroacetic} \mathrm{acid,}$ triturate (f) triethylamine $(2.1 \mathrm{eq}), \mathrm{N}$ hydroxybenzotriazole (3.0 eq), $\mathrm{THPONH}_{2}(3.0 \mathrm{eq})$, EDC (1.2 eq), DMF, $3.5 \mathrm{~h} 40^{\circ} \mathrm{C}$, rt $16 \mathrm{~h}(\mathrm{~g}) 4-$ ( $\mathrm{MeO}) \mathrm{PhMgBr}(5 \mathrm{eq}), \mathrm{THF}, 0^{\circ} \mathrm{C}$-rt overnight, then $\mathrm{NH}_{4} \mathrm{Cl}(\mathrm{h}) 4 \mathrm{~N} \mathrm{HCl}$, dioxane, $\mathrm{MeOH}$, triturate (i) $\mathrm{N}$ methylmorpholine (2.1 eq), N-hydroxybenzotriazole (1.2 eq), anisidine (1.5 eq), EDC (1.5 eq), DMF, rt. 
Table 1: MMP selectivity of studied compounds

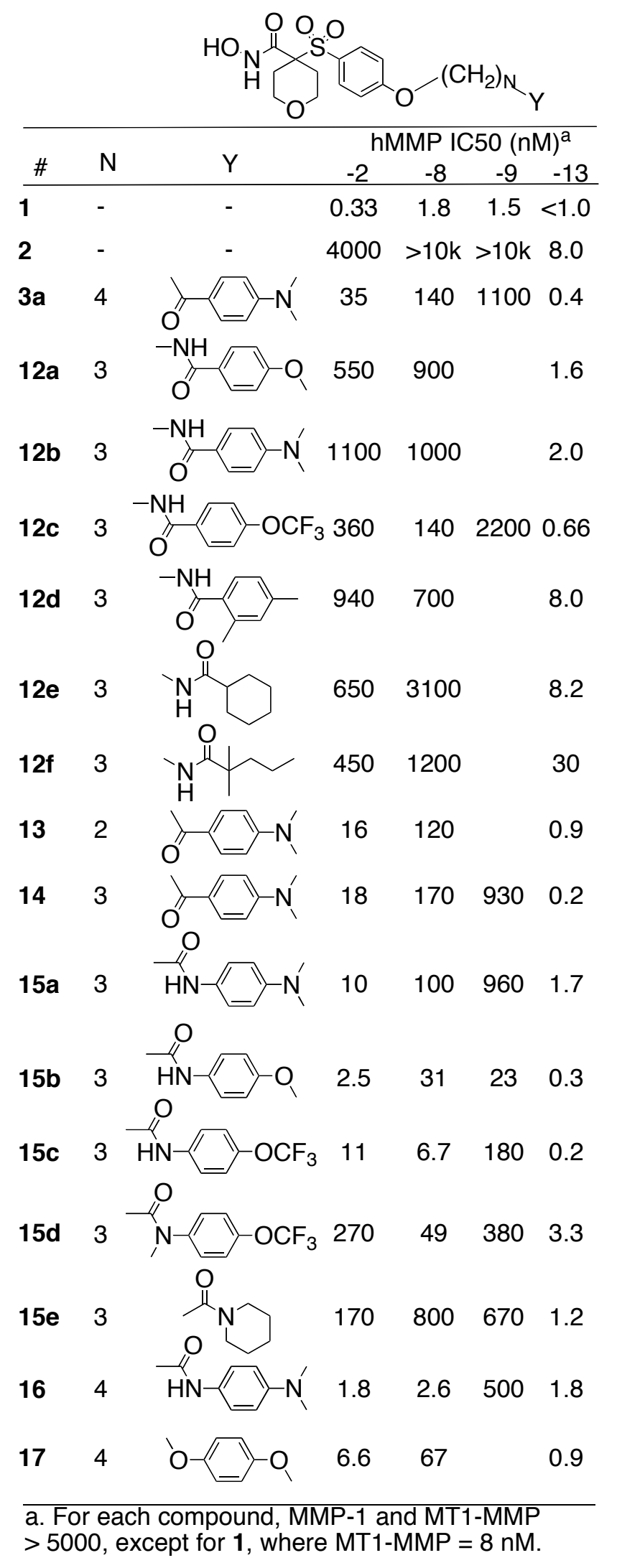




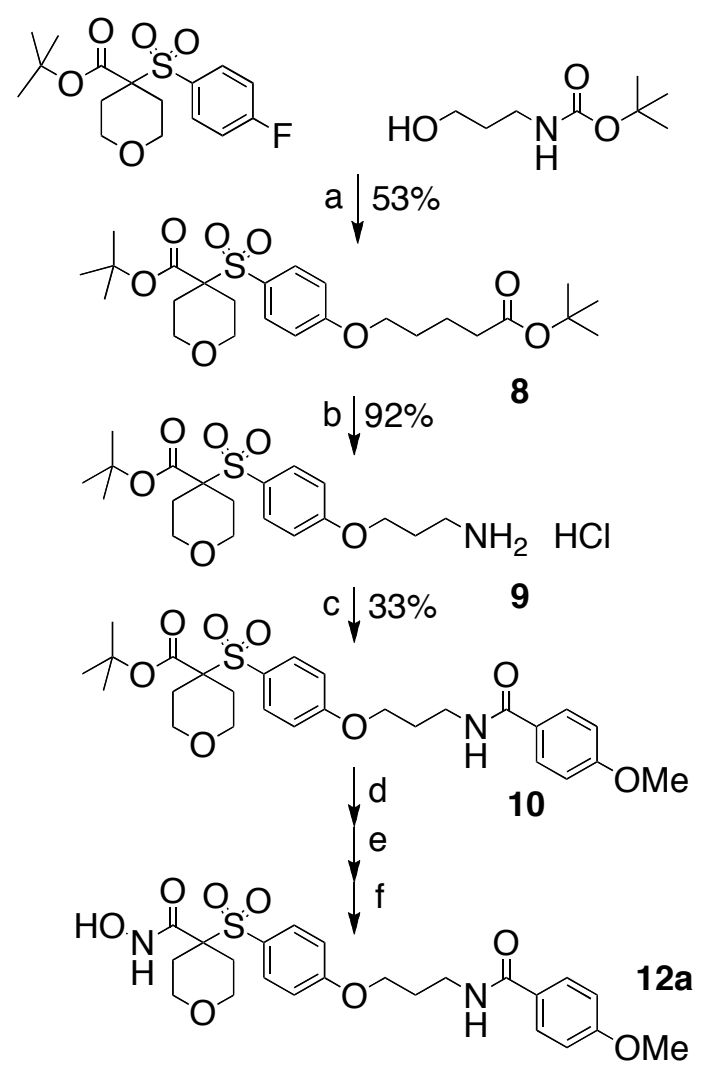

Scheme 2. Reagents and Conditions: (a) tert-butyl $\mathrm{N}$-(3-hydroxypropyl)carbamate (1.1 eq), $\mathrm{NaH}$ (1.2 eq), DMF, $0^{\circ} \mathrm{C}, 18 \mathrm{~h}$ (b) $4 \mathrm{~N} \mathrm{HCl} /$ dioxane, $1 \mathrm{~h}$ (c) DMF, triethylamine (1.2 eq), anisoyl chloride (1.2 eq) (d) trifluoroacetic acid, $3 \mathrm{~h}$, conc. at $50^{\circ} \mathrm{C}$, quant. (e) N-methylmorpholine (2.1 eq), $\mathrm{N}$ hydroxybenzotriazole (1.2 eq), $\mathrm{THPONH}_{2}(1.5 \mathrm{eq})$, EDC (1.5 eq), DMF, 3 days (f) $4 \mathrm{~N} \mathrm{HCl}$. dioxane, $\mathrm{MeOH}, 1 \mathrm{~h}$, conc., triturate 
